\title{
User frequency and microbial contaminants of traditional oral powdered herbal formulations in Ogbomoso, Nigeria
}

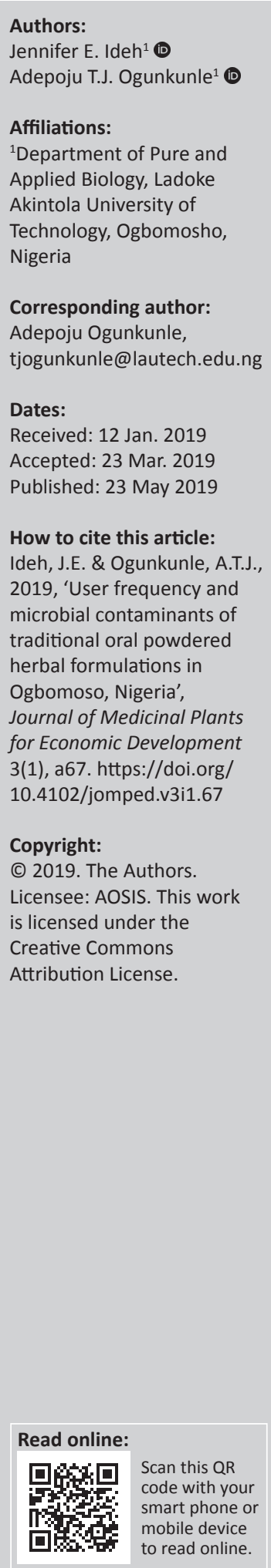

Background: Being natural, herbal products are often perceived as safe but studies have shown that they may not be free of pathogenic microorganisms. The extent of microbial contaminants of traditional oral powdered herbal formulations (TOPHFs) in Ogbomoso, Nigeria, is not known, while the frequency of users of these drugs in the study area has not been reported.

Aim: To evaluate the microbial contaminants of TOPHFs marketed in Ogbomoso Nigeria, identify the risk factors associated with their production and handling, and determine the frequency of users of the drugs.

Setting: Ogbomoso, Nigeria.

Methods: Fifteen manufacturers of TOPHFs listed the health conditions that are indicated for their drugs, while 125 residents provided information on their preference for those drugs. The questionnaires were analysed using descriptive statistics (frequency counts and percentages). Packaging and/or handling and level of personal and environmental hygiene of the manufacturers were examined and analysed for significance of their influence on contamination of drugs using chi-square test. Using pour plate method and following standard procedures, 12 samples of TOPHFs were analysed to quantify their bacterial and fungal contaminants.

Results: The TOPHFs were indicated for 17 different types of health conditions with $60 \%$ of the sampled population being prolonged and regular users. The personal and environmental hygiene levels of the manufacturers fell short of acceptable standard. Ten out of the 12 samples analysed were heavily contaminated (i.e. above WHO limits) with yeasts/moulds and faecal coliforms such as Enterobacteria, 9 with Streptococcus and 6 with pathogenic bacterial species such as Staphylococcus and Salmonella. There was a significant association of TOPHFs contamination with manufacturers' level of formal education $(p=0.001)$, solid waste management ( $p=0.015)$ and methods of updating knowledge and expertise $(p=0.004)$, thus making these 3 the risk factors associated with contamination of the drugs.

Conclusion: Use of TOPHFs is popular among the residents of Ogbomoso, but there is a high rate of contamination of these drugs with some potentially pathogenic organisms because of insufficient quality control in their production and handling.

Keywords: Microbial contamination; Pathogenic organisms; Risk factors; Herbal drug standardisation; Traditional herbal medicine practice.

\section{Introduction}

The survey by the World Health Organization (1988) indicated that about $70 \%-80 \%$ of the world population, particularly in the developing countries, rely on non-conventional medicines mainly of herbal origins for their primary health care. This is because herbal medicines are accessible and are considered cheaper than orthodox medications (Wachtel-Galor \& Benzie 2011). Therefore, the origin, quality and safety of herbal preparations are also of great concern. Standardisation of herbal medicine has been explained on the basis of reproducible efficacy and safety, and the quality of plant materials or preparations is of utmost importance in this direction (Kunle et al. 2012; WHO 2004).

Bauer (1998) showed that the quality criteria for herbal drugs are based on a clear scientific definition of the raw materials. It is, however, difficult to establish comprehensive quality for 
herbal drugs because of 'professional secrecy' of herbalists. In order to improve the purity and safety of the products, observation of basic hygiene during preparation and the knowledge of microbial contamination levels are desirable. The quality assessment of herbal formulations is very important in order to justify their acceptance in the modern system of medicine. It is thus mandatory that microbiological limit tests of herbal medicinal preparations, especially the powdered forms, be performed to ensure that the products are safe for consumption.

Various kinds of herbal preparations are used to treat different ailments such as piles, urinary tract infections, malaria and typhoid fever in Nigeria (Onyiapat, Okoronkwo \& Ogbonnaya 2011; Oreagba, Oshikoya \& Amachree 2011). Most of these herbal preparations are used in different forms and may carry a large number of microorganisms originating from the soil, usually adhering to leaves, stems, flowers, seeds and root of herbs (Adeleye, Okogi \& Ojo 2005). The occurrence of pathogenic bacteria and fungi in plant samples has been reviewed and reported by Kneifel, Zech and Kopp (2002) and Idu, Erahbor and Idele (2011), respectively.

In Nigeria, there appears to be an overwhelming increase in the public awareness and usage of African traditional medicinal products in the treatment and/or prevention of diseases (Ekeopara \& Ugoha 2017; Oreagba 2011). Although herbal products are often perceived as being natural and safe (Ekor 2013), they may, after all, not be free from microbial contaminants (Ekor 2013). A great number of residents in Ogbomoso are believed to depend on the services and products from traditional herbalists for their medical needs (Ogunkunle \& Ashiru 2011). However, information on the microbial load of these herbal products is not available in the literature. A study that evaluated the bacterial contamination of powdered herbal medicinal preparations sourced from outlets in different parts of Kaduna, Nigeria, showed that a number of these products were contaminated with Salmonella typhi, Shigella spp., Escherichia coli and Staphylococcus aureus (Abba 2009).

In Ogbomoso and many rural settlements in Africa, the majority of the powdered herbal formulations are homemade, being formulated by the traditional physicians. It is therefore important to subject samples of these powdered herbal formulations to tests looking at the various stages of raw material procurement, preparation, packaging, storage and transportation. This is particularly important because the preparations are taken orally without further purification process.

Although the report of Abba et al. (2009) indicated a widespread microbial contamination of herbal products from Kaduna, it gave no record of people that were exposed to the risk of contracting diseases because of the pathogens enumerated in the study. Arising from this observation, this study investigated the frequency of users of the various forms of powdered herbal products in Ogbomoso. This is one of the practical ways to estimate the extent of risk posed if such contaminants occur in the herbal products.

The objectives of the study are to identify the categories of the frequent users of these products and the proportion of the population of the residents that consume them, to evaluate the environmental conditions of the manufacturing locations with the view to determining their level of suitability, to document the storage and packaging methods adopted by the manufacturers, to examine the microbial contaminants in the powdered herbal formulations and to identify the risk factors associated with the production and handling of the drugs.

\section{Materials and methods Target population and sampling methods used in the study}

This study was conducted in Ogbomoso, Nigeria. It is located around latitude $8.1333 \mathrm{~N}$ and longitude $4.2567 \mathrm{E}$, covering Surulere, Ogbomoso north, Ogbomoso south, Orire and Ogo Oluwa local government areas (LGAs). The two categories of target population for the study were the community residents and the traditional herbal medical practitioners (THMPs) in the study area. The samples consisted of 125 residents (males and females) selected using stratified sampling technique (Gupta 2011), with each of the 5 LGAs taken as a stratum, and 17 randomly sampled THMPs, consisting of 4 from each of Ogbomoso north and south, and 3 from the other 3 LGAs.

Two types of questionnaires were developed by the authors and administered, the first to the community residents (numbering 25 in each LGA) having 2 sections A and B. Section A had 8 questions on the demographic profile of the respondents, while Section B consisted of 12 questions that were designed to gather information on preference and frequency of use of powdered herbal formulations. There were 4 sections named A, B, C and D in the second questionnaire that was administered on 17 THMPs recruited.

Section A sought the herbal healers' socio-demographic data with 11 questions. Section B with 9 questions was used to gather information on the types of powdered herbal formulations they manufactured and sold, and the indications for the drugs. Section $C$ with 3 questions was used to seek information on the involvement of children in the preparation of the powdered herbal formulations. Section D had 7 questions and was used to indirectly assess the herbal practitioners' personal and environmental hygiene as well as the storage and packaging of their herbal formulations. Copies of both questionnaires were administered in the company of four research assistants. Illiterate respondents were orally interviewed based on the items in the questionnaire, and their responses were appropriately recorded. Anonymity of all the participants was ensured by assigning alphabet codes to their questionnaires. 


\section{Sample collection}

Samples of powdered herbal formulations were procured from the manufacturers in various containers, such as glass/ plastic bottle, low-density polythene bags and used paper/ envelope. The herbal formulations were placed in sterile air tight plastic bags placed in an ice box and transported to the Microbiology and Nanotechnology Laboratory, Department of Pure and Applied Biology, Ladoke Akintola University of Technology, Ogbomoso, Nigeria, where they were refrigerated before laboratory analyses were carried out. Out of the 17 THMPs contacted during the survey, only 10 voluntarily offered to dispense some of their products, and a total of 32 medications variously indicated for the treatment of 12 health conditions altogether were collected.

\section{Laboratory techniques}

The samples were evaluated for their microbial load, moisture content (\%) and $\mathrm{pH}$. A total number of 12 herbal preparations used for the treatment of 12 different health conditions were randomly picked from the 32 samples collected. In estimating the microbial load of the samples, $1 \mathrm{~g}$ of each powdered drug was weighed aseptically and suspended in $10 \mathrm{~mL}$ sterile distilled water for serial dilution. Appropriate dilutions of $10^{-1}, 10^{-2}$ and $10^{-3}$ fold were done and $0.1 \mathrm{~mL}$ of the $10^{-3}$ aliquot was used to inoculate the three plates of appropriate agar using pour plate method (Shweta et al. 2017). The agars used for enumeration and isolation of microorganisms were plate count agar for aerobic bacteria, Salmonella-Shigella agar for Salmonella, mannitol salt agar for Staphylococcus, potato-dextrose agar (PDA) for yeasts and moulds and MacConkey agar for coliforms. All the plates, for bacterial enumeration including their controls, were incubated at $35{ }^{\circ} \mathrm{C}-38{ }^{\circ} \mathrm{C}$ for $24-36$ hours. Those of PDA for yeasts and moulds were incubated at $25{ }^{\circ} \mathrm{C}-28{ }^{\circ} \mathrm{C}$ for 48 hours. The controls consisted of only the respective plates with the agars which were not inoculated with standard strains of the microorganisms under study. At the end of the incubation, the numbers of distinct colonies were determined using a colony counter, and the results were used to calculate the microbial load in each case, taking into consideration the dilution factor.

The moisture content (MC) was determined by weighing exactly $2 \mathrm{~g}$ of the sample on S.METTLER laboratory balance with K-300 g/0.01 g precision into a clean porcelain crucible. This was transferred into the hot air oven set at $105^{\circ} \mathrm{C}$ and heated for 24 hours, after which the crucible containing the sample was cooled in the desiccator at room temperature and weighed. The MC was then calculated using the following formula (Gautam \& Bhadauria 2008):

(Weight of crucible + sample before heating) -

$M C=\frac{\text { (Weight of crucible }+ \text { sample after heating })}{\text { Weight of sample }} \times 100[$ Eqn 1$]$

where $\mathrm{MC}=$ moisture content.
Prior to the determination of the $\mathrm{pH}$ of the samples, calibration of the electrode of the $\mathrm{pH}$ meter was performed with the Automatic Temperature Compensation (ATC). Sample solution was prepared by weighing $5 \mathrm{~g}$ of the sample into a $200 \mathrm{~mL}$ beaker and adding $100 \mathrm{~mL}$ of distilled water with shaking to obtain a homogenous solution. Thereafter, the electrode was immersed into the solution and the results were read once the reading had stabilised. All the analyses were carried out in three replicates and the mean was calculated for each.

\section{Statistical analyses}

Quantitative and categorical data collected on each variable studied were described as proportion and then computed as a percentage of the appropriate population sample in accordance with the objectives of the study. Using chi-square test, all the variables (personal, systemic and environmental) relating to manufacturing, packaging and handling of the drugs were considered in analysing the significance of difference in distribution of contamination of traditional oral powdered herbal formulations (TOPHFs) using SPSS version 20.0. The difference in distribution was considered significant at $p<0.05$. The microbial load of each group/species of microorganisms isolated was calculated as a percentage or relative abundance of the total load across the 12 drugs analysed.

\section{Results}

\section{Information about the traditional herbal medical practitioners and their activities}

According to the entries in Table 1, out of the 17 THMPs recruited in the study, 13 (76.5\%) were males, while $4(23.5 \%)$ were females, out of which 10 (58.8\%) were over 50 years of age. About $70.0 \%$ of the healers had only primary and secondary education; however, up to $65.0 \%$ of them had practised in the profession for more than 30 years. Historically, these people came into the profession by descent (being their family trade/profession), while few others either combined some form of training with this option or depended on natural gift/talent to become traditional healers. The THMPs updated their knowledge of medical practice through a wide range of choices such as by intuition (35.3\%), attendance at health talks/meetings (11.0\%), and electronic media (5.9\%); while $47.8 \%$ of them adopted various forms of combination of these and other choices.

Of the 17 THMPs contacted, only 15 produced, sold and applied TOPHFs indicated for 17 different types of health conditions including maintenance of general body homeostasis and in the management of some dreaded diseases such as high blood pressure and diabetes. All the THMPs (100.0\%) produced TOPHFs for malaria therapy, and also sizeable proportions of them $(6.7 \%$ in each case) produced the powdered drugs for female infertility, onchocerciasis, diabetes, stomach ulcer and yellow fever (Table 2). 
TABLE 1: Information on the traditional herbal healers included in the study.

\begin{tabular}{|c|c|c|c|}
\hline \multirow[t]{2}{*}{ Parameters } & \multicolumn{3}{|c|}{ Number of participants } \\
\hline & Male & Female & Total $(N=17)$ \\
\hline \multicolumn{4}{|l|}{ Age (years) } \\
\hline $31-40$ & 4 & 0 & 4 \\
\hline $41-50$ & 2 & 1 & 3 \\
\hline$>50$ & 7 & 3 & 10 \\
\hline \multicolumn{4}{|l|}{ Formal education } \\
\hline None & 0 & 2 & 2 \\
\hline Primary & 7 & 1 & 8 \\
\hline Secondary & 3 & 1 & 4 \\
\hline OND/NCE & 1 & 1 & 2 \\
\hline HND/degree & 1 & 0 & 1 \\
\hline \multicolumn{4}{|l|}{ Experience (years) } \\
\hline$<10$ & 2 & 0 & 2 \\
\hline 10-20 & 1 & 1 & 2 \\
\hline $21-30$ & 1 & 1 & 2 \\
\hline$>30$ & 9 & 2 & 11 \\
\hline \multicolumn{4}{|l|}{ Professional history } \\
\hline By descent & 11 & 4 & 15 \\
\hline By training & 0 & 0 & 0 \\
\hline Both by descent and training & 1 & 0 & 1 \\
\hline Others $\dagger$ & 1 & 0 & 1 \\
\hline \multicolumn{4}{|l|}{ Manufacturer of powdered herbs } \\
\hline Yesł & 11 & 4 & 15 \\
\hline No & 2 & 0 & 2 \\
\hline \multicolumn{4}{|l|}{ Update of knowledge in medical practice } \\
\hline By intuition (A) & 5 & 1 & 6 \\
\hline Attendance of meetings/health talks (B) & 2 & 0 & 2 \\
\hline Electronic media $(\mathrm{C})$ & 1 & 0 & 1 \\
\hline Internet (D) & 0 & 0 & 0 \\
\hline$A$ and $B$ & 2 & 3 & 5 \\
\hline$A, B$ and $C$ & 1 & 0 & 1 \\
\hline$A, B, C$ and $D$ & 2 & 0 & 2 \\
\hline
\end{tabular}

OND, Ordinary National Diploma, NCE, Nigeria Certificate in Education, HND, Higher National Diploma.

$\dagger$, Talent from God

$\$$ Fifteen of the 17 herbal healers produced powdered herbal formulations for oral use and their residential homes doubled as factories, with none of them having evidence of registration of their products with NAFDAC (i.e. national food and drug administration and control).

TABLE 2: List of health conditions claimed by the traditional healers to have been treated with powdered herbal formulations manufactured and marketed by them in Ogbomoso, Nigeria.

\begin{tabular}{llcc}
\hline Number & $\begin{array}{l}\text { Health condition/type } \\
\text { of powdered herb }\end{array}$ & $\begin{array}{c}\text { Number of } \\
\text { manufacturers }(\boldsymbol{N}=15)\end{array}$ & $\begin{array}{c}\text { Samples } \\
\text { for analysis }\end{array}$ \\
\hline 1 & Arthritis and rheumatism & 2 & $+(1)$ \\
2 & Back and/waist pain & 2 & $+(1)$ \\
3 & Bareness/female infertility & 1 & - \\
4 & Blood enricher/enhancer & 4 & $+(2)$ \\
\hline 5 & Blood purifier/thinner & 6 & $+(2)$ \\
6 & Body itch/onchocerciasis & 1 & - \\
7 & Convulsion & 2 & $+(1)$ \\
8 & Diabetes & 1 & - \\
9 & Male erectile dysfunction & 2 & $+(2)$ \\
10 & Gonorrhoea & 2 & $+(1)$ \\
11 & High blood pressure & 8 & $+(3)$ \\
12 & Jaundice/anaemia & 6 & - \\
13 & Malaria fever & 15 & $+(7)$ \\
14 & Piles & 14 & $+(6)$ \\
15 & Typhoid & 11 & $+(5)$ \\
16 & Ulcer (stomach, duodenum, peptic) & 1 & - \\
17 & Yellow fever & 1 & $+(1)$ \\
\hline Total number of powdered samples collected & & $\mathbf{3 2}$ \\
\hline,+ available and collected for laboratory analysis, and number of samples collected are \\
indicated in parentheses; - not available for laboratory analysis.
\end{tabular}

\section{Information on the use of traditional oral powdered herbal formulations among the residents of the study area}

Up to $99(70.0 \%)$ of the 125 community residents that were included in the survey had records of preference for traditional oral powdered drugs. However, 24 (19.0\%) of them had used the drugs in the past, while $60(75.0 \%)$ are still using the herbal formulations. Those residents that used TOPHFs in the past but discontinued use $(19.0 \%)$ as well as those who never used the products nor wished to do so $(16.0 \%)$ enumerated certain complaints. Notable among the complaints are stomach disorder, awful taste, perceived unhygienic mode of preparation, ineffectiveness, lack of information on the constituents, unknown safety level, inconstant dosage, and lack of manufacturing and expiry dates. The majority of the residents were traders, students, farmers, teachers and artisans, which constituted 28.0\%, $17.6 \%, 16 \%, 14.4 \%$, and $13.6 \%$, respectively, of the sample (Table 3). About $83.0 \%$ of the 99 users of TOPHFs sourced the drugs from traditional healers or their hawkers; $9.1 \%$ from licensed/registered manufacturers in the form of herbal capsules, tablets etc.; and 8.1\% sourced from both. Of the 75 regular users of TOPHFs, $93.3 \%$ always used the products,

TABLE 3: Information about the use of traditional oral powdered herbal formulations among the residents of Ogbomoso, Nigeria.

\begin{tabular}{|c|c|c|}
\hline Options/categories & Frequency & $\%$ \\
\hline \multicolumn{3}{|l|}{ Community residents involved in the study $(N=125)$} \\
\hline Business/trading/petty trading & 35 & 28.0 \\
\hline Schooling & 22 & 17.6 \\
\hline Farming & 20 & 16.0 \\
\hline Teaching & 18 & 14.4 \\
\hline Artisans & 17 & 13.6 \\
\hline Apprenticeship & 8 & 6.4 \\
\hline Civil/public service & 3 & 2.4 \\
\hline Driving & 2 & 1.6 \\
\hline Total & 125 & 100.0 \\
\hline \multicolumn{3}{|l|}{ Preference for use of TOPHFs $(N=125)$} \\
\hline Used PHFs, even up till time of the study & 75 & 60.0 \\
\hline Used PHFs in the past but no longer use them $\dagger$ & 24 & 19.0 \\
\hline $\begin{array}{l}\text { Never used PHFs and did not wish to use them as at the } \\
\text { time of study: }\end{array}$ & 20 & 16.0 \\
\hline Never used PHFs but could do so if the need arises & 6 & 5.0 \\
\hline Total & 125 & 100.0 \\
\hline \multicolumn{3}{|l|}{ Sources of TOPHFs $(N=99)$} \\
\hline $\begin{array}{l}\text { Category I: Local herbal healers/hawkers only } \\
\text { (who dispense PHFs to buyers/users on request) }\end{array}$ & 82 & 82.8 \\
\hline $\begin{array}{l}\text { Category II: Licensed herbal remedies manufacturers only } \\
\text { (herbal capsules, tablets, etc.) }\end{array}$ & 9 & 9.1 \\
\hline Both categories I and II sources & 8 & 8.1 \\
\hline Total & 99 & 100.0 \\
\hline \multicolumn{3}{|l|}{ Frequency and purpose of using TOPHFs $(N=75)$} \\
\hline $\begin{array}{l}\text { Takes always and only when the individual is ill, believing that } \\
\text { PHFs are very safe for consumption and potent when used }\end{array}$ & 70 & 93.3 \\
\hline $\begin{array}{l}\text { Takes usually and only when the individual is ill, believing } \\
\text { that PHFs are fairly safe and potent }\end{array}$ & 5 & 6.7 \\
\hline Takes always, that is, whether the individual is ill or not & 0 & 0.0 \\
\hline Takes sometimes only when the individual is ill & 0 & 0.0 \\
\hline Takes rarely when he or she is ill & 0 & 0.0 \\
\hline Total & 75 & 100.0 \\
\hline
\end{tabular}

TOPHFs, traditional oral powdered herbal formulations; PHFs, powdered herbal formulations. $\dagger$, Reasons for discontinuing included stomach disorder, perceived unhygienic preparation and ineffectiveness of TOPHFs.

$\ddagger$, Reasons for non-usage of TOPHFs included awful taste, perceived unhygienic preparation, lack of information on the constituents, safety, dosage, manufacturing and expiry dates. 
believing that they were safe for consumption and potent when used. On the other hand, the balance of $6.7 \%$ of them usually did so, with the belief that the products were fairly safe and potent (Table 3).

\section{Environmental conditions of traditional herbal medical practitioners and microbial contamination of their products}

The information in Table 4 shows that all the THMPs engaged the services of persons under 18 years of age at various stages

TABLE 4: Description of environmental and handling conditions in the manufacture of traditional powdered herbal drugs in Ogbomoso, Nigeria.

\begin{tabular}{|c|c|c|}
\hline \multirow[t]{2}{*}{ Activities/conditions/facilities } & \multicolumn{2}{|c|}{ Frequency } \\
\hline & $N=15$ & $\%$ \\
\hline \multicolumn{3}{|l|}{ Engagement of services of children } \\
\hline Yest & 15 & 100 \\
\hline No & 0 & 0.0 \\
\hline \multicolumn{3}{|l|}{ Main source of water } \\
\hline Well & 10 & 66.7 \\
\hline Stream & 0 & 0.0 \\
\hline Bore hole & 5 & 33.3 \\
\hline \multicolumn{3}{|c|}{ Storage for marketing or for administration $\sharp$} \\
\hline Plastic container with lid & 10 & 66.7 \\
\hline Glass bottle with lid & 4 & 26.7 \\
\hline Others $\S$ & 1 & 6.6 \\
\hline \multicolumn{3}{|c|}{ Packaging of products for marketing/ administration } \\
\hline Glass bottle & 2 & 13.3 \\
\hline Plastic bottle & 4 & 26.7 \\
\hline Low-density polyethene (nylon) & 8 & 53.3 \\
\hline Used paper & 1 & 6.7 \\
\hline \multicolumn{3}{|l|}{ Human waste disposal practices } \\
\hline Nearby bush & 1 & 6.7 \\
\hline Pit latrine & 9 & 60.0 \\
\hline Water closet & 2 & 13.3 \\
\hline Others & 3 & 20.0 \\
\hline \multicolumn{3}{|l|}{ Solid waste disposal practices } \\
\hline Open burning & 1 & 6.7 \\
\hline Nearby bush & 1 & 6.7 \\
\hline Open, nearby dump site & 6 & 40.0 \\
\hline Open, faraway dump site & 7 & 46.6 \\
\hline
\end{tabular}

$\dagger$, Persons of less than 18 years of age engaged in open air/courtyard drying and grinding of herbs. \$. Storage containers being op ened as frequent as the drug was to be dispensed.

$\S$, Storage in sacks especially by large scale/wholesale manufacturers.

- Public/community toilet facilities. of manufacturing the drugs. Moreover, about $67 \%$ of them sourced water from wells, while less than $34 \%$ depended on bore hole water. The majority of the healers $(66.6 \%)$ used covered plastic containers for storage of the drugs and lowdensity polythene bags (53.3\%) to package their products for marketing/administration. A larger proportion (about 60.0\%) of them used pit latrines as facility for human waste disposal, while the observed solid waste disposal practices among them consisted of open burning $(6.7 \%)$, disposal to nearby bush (6.7\%), and on nearby/faraway dump sites (86.6\%).

High level of microbial contaminants was observed in the herbal products. A total of 10 out of the 12 samples were contaminated, while the remaining two (back/waist pain and convulsion remedies) were free of the microbial contaminants. As indicated in Table 5, 10 of the herbal formulations were contaminated with yeasts/moulds and faecal coliforms (above $10^{4} / 10^{3} \mathrm{cfu} / \mathrm{g}$, respectively, recommended as maximum limit by WHO). Nine of the remedies were contaminated with Streptococcus spp. (above $10^{4} \mathrm{cfu} / \mathrm{g}$ ); six with pathogenic bacterial species such as Staphylococcus spp. (above $10^{4} \mathrm{cfu} / \mathrm{g}$ ) and Salmonella spp. (above zero cfu/g). The range of observed contamination calculated as mean $\mathrm{cfu} / \mathrm{g}$ of the powdered drugs was $1.00 \times 10^{5}-1.50 \times 10^{7}$ of yeast/moulds, $1.00 \times 10^{5}$ - $1.06 \times 10^{7}$ of Enterobacteria, $1.50 \times 10^{5}-1.34 \times 10^{7}$ of Streptococcus spp., $1.50 \times 10^{5}-6.75 \times 10^{6}$ of Staphylococcus spp. and $7.00 \times 10^{5}-5.65 \times 10^{6}$ of Salmonella spp. (Table 5).

Figure 1 shows that the TOPHFs were mostly contaminated (24.3\%) by Streptococcus spp. followed closely by Salmonella spp. (23.2\%), while the least observed microbial contaminant was Enterobacteria (14.7\%). Out of the nine variables tested, Table 6 shows that there was a significant association of TOPHFs contamination with manufacturers' level of formal education $(p=0.001)$, solid waste management strategies $(p=0.015)$ and methods of updating their knowledge and expertise $(p=0.004)$.

\section{Discussion}

The THMPs contacted claimed that the various TOPHFs they produced are indicated for many classes of diseases ranging

TABLE 5: Microbial and physico-chemical attributes of some samples of traditional oral powdered herbal formulations marketed in Ogbomoso, Nigeria. $\dagger$

\begin{tabular}{|c|c|c|c|c|c|c|c|c|}
\hline \multirow{2}{*}{$\begin{array}{l}\text { TOPHFs or health conditions } \\
\text { treated with TOPHFs }\end{array}$} & \multirow{2}{*}{$\begin{array}{l}\text { Manufacturer's } \\
\text { code }\end{array}$} & \multicolumn{5}{|c|}{ Microbial load in the PHFs (cfu/g) } & \multirow{2}{*}{$\begin{array}{c}\text { Moisture } \\
\text { content (\%) }\end{array}$} & \multirow[t]{2}{*}{$\mathrm{pH}$} \\
\hline & & Yeasts and moulds & Enterobacteria & Salmonella spp. & Streptococcus spp. & Staphylococcus spp. & & \\
\hline Arthritis/rheumatism & $\mathrm{K}$ & $2.20 \times 10^{6}$ & $2.65 \times 10^{6}$ & - & $2.45 \times 10^{6}$ & $1.50 \times 10^{5}$ & 6.8 & 5.8 \\
\hline Back/waist pain & $\mathrm{C}$ & - & - & - & - & - & 1.2 & 8.6 \\
\hline Blood enricher/enhancer & $\mathrm{N}$ & $1.00 \times 10^{5}$ & $1.00 \times 10^{5}$ & - & $1.50 \times 10^{5}$ & - & 9.0 & 4.3 \\
\hline Blood purifier & 1 & $1.50 \times 10^{7}$ & $1.29 \times 10^{6}$ & $5.45 \times 10^{6}$ & $1.48 \times 10^{6}$ & $2.50 \times 10^{6}$ & 5.2 & 5.7 \\
\hline Convulsion & C & - & - & - & - & - & 1.0 & 5.5 \\
\hline Male erectile dysfunction & A & $1.75 \times 10^{6}$ & $1.90 \times 10^{6}$ & $9.50 \times 10^{5}$ & $3.20 \times 10^{6}$ & $2.45 \times 10^{6}$ & 11.0 & 8.2 \\
\hline Gonorrhoea & B & $2.50 \times 10^{6}$ & $2.20 \times 10^{6}$ & $1.75 \times 10^{6}$ & $2.50 \times 10^{6}$ & $1.35 \times 10^{6}$ & 9.1 & 9.7 \\
\hline High blood pressure & M & $1.20 \times 10^{6}$ & $5.40 \times 10^{6}$ & $7.00 \times 10^{5}$ & $8.80 \times 10^{6}$ & - & 5.2 & 3.4 \\
\hline Malaria & $\mathrm{D}$ & $4.30 \times 10^{6}$ & $6.40 \times 10^{5}$ & - & $7.40 \times 10^{6}$ & $6.75 \times 10^{6}$ & 7.6 & 6.3 \\
\hline Piles & $\mathrm{H}$ & $2.60 \times 10^{6}$ & $7.00 \times 10^{5}$ & $6.00 \times 10^{5}$ & - & - & 8.4 & 6.0 \\
\hline Typhoid & J & $1.46 \times 10^{7}$ & $1.06 \times 10^{7}$ & $5.65 \times 10^{6}$ & $1.34 \times 10^{7}$ & $5.95 \times 10^{6}$ & 7.1 & 5.8 \\
\hline Yellow fever & 1 & $1.80 \times 10^{6}$ & $2.00 \times 10^{5}$ & - & $8.50 \times 10^{5}$ & - & 5.4 & 6.1 \\
\hline WHO limit & - & $10^{4} / \mathrm{g}$ & $10^{3} / \mathrm{g}$ & $0 / g$ & $10^{4} / \mathrm{g}$ & $10^{4} / \mathrm{g}$ & 0.0 & - \\
\hline
\end{tabular}

TOPHFs, traditional oral powdered herbal formulations.

$\dagger$, Values are means of three replicates. 
from common ill health conditions such as malaria to some of the dreaded ailments such as hypertension and diabetes. In a related study, Ogunkunle and Ashiru (2011)

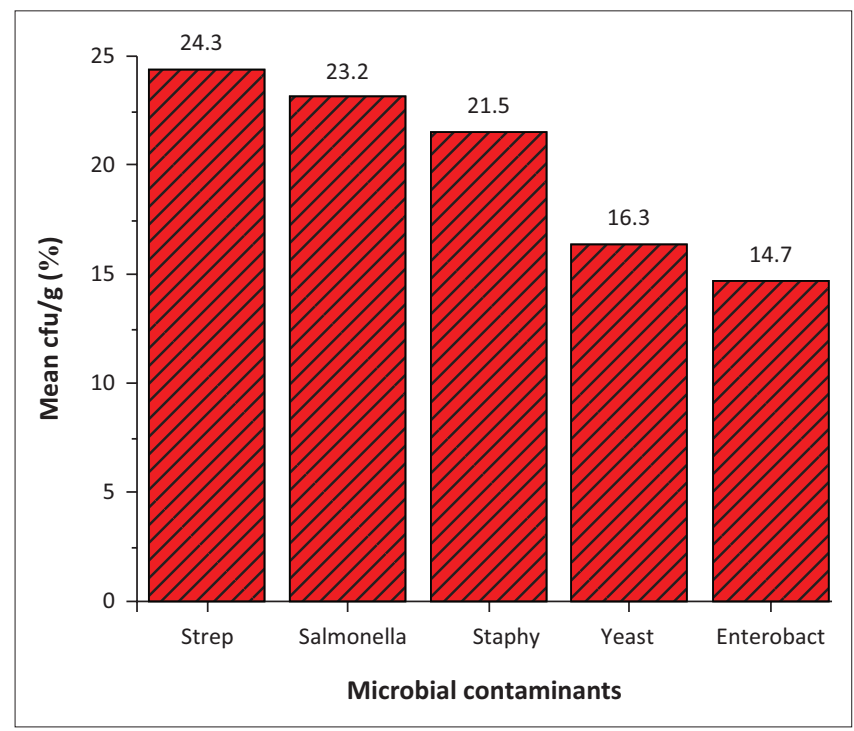

Mean was calculated based on the number of herbal formulations contaminated by each organism from the 12 samples analysed; Strep. = Streptococcus spp.; Salmonella = Salmonella spp; Staphy = Staphylococcus spp.; Yeast $=$ yeast and moulds; Enterobact. $=$ Enterobacteria

FIGURE 1: Microbial contaminants in some traditional oral powdered herbal formulations marketed in Ogbomoso Nigeria. have enumerated 14 different classes of diseases that were satisfactorily healed or relieved with herbal remedies in Ogbomoso including fevers $(62.4 \%)$, gastrointestinal $(68.5 \%)$, gynaecological $(38.3 \%)$, and respiratory tract $(19.2 \%)$ disorders and skin infections $(11.6 \%)$. The fact that the majority of the THMPs involved in this study were manufactures of drugs for the treatment or management of malaria (100\%) and piles $(93.3 \%)$ was a pointer to the probability that these ill health conditions are the most prevalent among the residents of Ogbomoso.

This study has also indicated that $79.0 \%$ of the sampled residents of Ogbomoso were users of TOPHFs at one time or another, while $60.0 \%$ were active users. These results approximately fell in line with that of the World Health Organization (1998) in which the population of users of herbal medicine in developing countries had been estimated to be between $70.0 \%$ and $80.0 \%$. Also, the study by Ogunkunle and Ashiru (2011), estimated the proportion of regular users of herbal medicine in Ogbomoso to be $78.0 \%$.

This study has shown that most of the powdered herbal drugs examined were contaminated by yeasts and coliform bacteria, which is beyond the recommended maximum limits by the World Health Organization.

TABLE 6: Identification of possible risk factors in microbial contamination of powdered herbal formulations manufactured in Ogbomoso, Nigeria.

\begin{tabular}{|c|c|c|c|c|c|}
\hline \multirow[t]{2}{*}{ Number } & \multirow[t]{2}{*}{ Variable } & \multirow[t]{2}{*}{ Options } & \multicolumn{2}{|c|}{ Quality of powdered herbs in relation to the variables $\dagger$} & \multirow[t]{2}{*}{$p$} \\
\hline & & & Contamination (\%) & Free of contamination $(\%)$ & \\
\hline \multirow[t]{2}{*}{1} & \multirow[t]{2}{*}{ Age of herbal healers } & $31-40$ years & 80.0 & 20.0 & \multirow{2}{*}{0.263} \\
\hline & & Above 50 years & 66.7 & 33.3 & \\
\hline \multirow[t]{5}{*}{2} & \multirow[t]{5}{*}{ Formal education } & None & 80.0 & 20.0 & \multirow{5}{*}{0.001} \\
\hline & & Primary & 93.3 & 6.7 & \\
\hline & & School Cert & 35.0 & 65.0 & \\
\hline & & OND/ACE/NCE & 100.0 & 0.0 & \\
\hline & & HND/degree & 80.0 & 20.0 & \\
\hline \multirow[t]{4}{*}{3} & \multirow[t]{4}{*}{ Practice experience } & Less than 10 years & 80.0 & 20.0 & \multirow{4}{*}{0.813} \\
\hline & & $10-20$ years & 80.0 & 20.0 & \\
\hline & & $21-30$ years & 80.0 & 20.0 & \\
\hline & & Above 30 years & 66.7 & 33.3 & \\
\hline \multirow[t]{2}{*}{4} & \multirow{2}{*}{$\begin{array}{l}\text { Update of knowledge } \\
\text { and expertise }\end{array}$} & Involving intuition as a strategy & 82.5 & 17.5 & \multirow{2}{*}{0.004} \\
\hline & & Not involving intuition as a strategy & 45.0 & 55.0 & \\
\hline \multirow[t]{3}{*}{5} & \multirow[t]{3}{*}{ Source of water } & Well & 67.5 & 32.5 & \multirow{3}{*}{0.743} \\
\hline & & Bore hole & 80.0 & 20.0 & \\
\hline & & Well and Borehole & 70.0 & 30.0 & \\
\hline \multirow[t]{3}{*}{6} & \multirow{3}{*}{$\begin{array}{l}\text { Storage medium of } \\
\text { powdered herbs }\end{array}$} & Plastic container & 65.7 & 34.3 & \multirow{3}{*}{0.650} \\
\hline & & Glass bottle & 73.3 & 26.7 & \\
\hline & & Others(e.g. sacks) & 80.0 & 20.0 & \\
\hline \multirow[t]{3}{*}{7} & \multirow{3}{*}{$\begin{array}{l}\text { Marketing/dispensing } \\
\text { medium }\end{array}$} & Low-density polyethene (nylon) & 62.2 & 37.8 & \multirow{3}{*}{0.069} \\
\hline & & Plastic bottles & 100.0 & 0.0 & \\
\hline & & Used paper & 90.0 & 10.0 & \\
\hline \multirow[t]{4}{*}{8} & \multirow{4}{*}{$\begin{array}{l}\text { Human waste disposal } \\
\text { methods }\end{array}$} & Nearby bush & 100.0 & 0.0 & \multirow{4}{*}{0.126} \\
\hline & & Pit toilet & 60.0 & 40.0 & \\
\hline & & Water closet & 70.0 & 30.0 & \\
\hline & & Others & 90.0 & 10.0 & \\
\hline \multirow[t]{4}{*}{9} & Solid waste disposal & Open burning & 80.0 & 20.0 & \\
\hline & & Nearby bush & 100.0 & 10.0 & 0015 \\
\hline & & Open, nearby dump site & 48.0 & 52.0 & 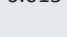 \\
\hline & & Open, faraway dump site & 84.0 & 16.0 & \\
\hline
\end{tabular}

OND, Ordinary National Diploma; ACE, Associatship Certificate in Education; NCE, Nigeria Certificate in Education; HND, Higher National Diploma.

$\dagger$, Contamination of powdered herbs (cfu/g) was calculated in terms of the proportion of the five categories of microorganisms examined occurring in excess of the limits set by the World Health Organization. 
Coliforms are members of the family Enterobacteriaceae and the most reliable indicators of recent faecal pollution. Thus, the test for their presence is an index of the degree of pollution, which may indicate a possible presence of harmful, disease-causing organisms (Baylis et al. 2011). These bacteria make up approximately $10.0 \%$ of the intestinal microorganisms of humans and other animals and are therefore used as indicator organisms. Faecal coliforms have the significance that if they are present in a substrate, then other harmful microorganisms such as Salmonella spp. may also be present (Akyala,Ajumobi \& Olayinka 2014; Butler 2005; Environmental Fact Sheet 2003). True to this belief, the locally made drugs analysed were also found to be contaminated by Streptococcus, Staphylococcus and Salmonella spp.

Similarly, high rates of contamination of traditional herbal products have been reported by Okunlola, Adewoyin and Odeku (2007) in south-western Nigeria; Abba et al. (2009) in Kaduna, Nigeria; Khanom et al. (2013) in Dhaka, Bangladesh; Onyambu et al. (2013) in Nairobi, Kenya; and Walther et al. (2016) in Mwanza city, Tanzania. The findings of this study are quite similar to those of Abba et al. (2009) in terms of heavy presence of pathogenic bacterial species such as Salmonella spp. in powdered herbal products, but it is at variance to those of Walther et al. (2016), which did not report the presence of pathogenic organisms. The absence of pathogenic microorganisms in an oral drug should not however be taken as a relief as certain microorganisms may not be pathogenic but objectionable. According to Islam et al. (2015), a species of microorganisms is objectionable if it can bring about the destruction of active ingredients in some drugs and thus can interfere with the functioning of a therapeutic product.

The growth of microorganisms is greatly influenced by both the physical and chemical nature of their environments. Among the physical factors that affect microbial growth are $\mathrm{MC}$ and $\mathrm{pH}$ of the growth medium (Lacoma 2018). Free flow of water is vital to microorganisms for their cells to exchange materials and for their metabolic activities. As a general rule, the more the moisture, the higher the growth in population of microorganisms (Lacoma 2018; Onilude, Igbinadolor \& Wakil 2010).

From the point of view of microbial contamination, MC is an important factor in the quality of herbal materials (Gautam \& Bhadauria 2008) and powdered herbal drugs. There is therefore little wonder that the TOPHFs for back/waist pain and convulsion with less than $2.0 \% \mathrm{MC}$ were both free of all the microorganisms identified in this study. In contrast, the other 10 powdered drugs examined with 5.2\% - 11.0\% MC were relatively heavily contaminated. Similar to this observation, Guatam and Bhadauria (2008) have reported higher fungal contamination of herbal fruit samples having higher MC.

Microorganisms also prefer a certain $\mathrm{pH}$ range in the substrate in which they grow. According to Lacoma (2018), most microorganisms are neutrophiles, preferring substrates with a neutral $\mathrm{pH}$ level (5.0-8.0), but others are alkalophiles, which prefer $\mathrm{pH}$ range of $8.5-11.5$, and few are acidophiles ( $\mathrm{pH}$ range of 1.0-2.0). Relative to these three categories of $\mathrm{pH}$ preference, none of the powdered herbal drugs evaluated can be classified as strictly acidic, their $\mathrm{pH}$ range being 3.4-9.7. This condition favours luxuriant growth of many species of bacteria (Lacoma 2018) and fungi (Gautam \& Bhadauria 2008) as observed in this study.

The kinds and magnitude of the bacterial species isolated in this study are indications of inadequate environmental sanitation measures in the cascade of powdered drugs production process (Onyambu et al. 2013), raw materials contamination (Enayatifard, Asgarirad \& Kazeni-Sani 2010) and effects of other factors which may be personal to the manufacturer, or systemic such as involvement of children. Engaging children in manufacturing processes, especially those exposing them to physical, biological or chemical hazards, can be at the risk of the children or at the expense of the owner of the enterprise, or both (Ogunsakin 2015). Moreover, children are characterised by their high inquisitiveness (Strocel 2013), short attention span and easy loss of focus (SCALE 2018), and they are therefore prone to committing errors, often without making a report for fear of being reprimanded. On account of these features, children constitute a potential source of TOPHF contamination in Ogbomoso even though this position cannot be substantiated by statistical evidence from this study (Table 6).

Environment-based possible causes of contamination in a drug or food-based industry include but are not limited to the source of water, storage medium of products, marketing and/or dispensing medium, and solid and/or human waste management techniques at the manufacturing site (Khanom et al. 2013). In this study, solid waste disposal method at the TOPHFs manufacturing sites was the only environmental factor that recorded significant association with drug contamination. It is therefore a risk factor that calls for attention. That absolute contamination was observed in the products of those manufacturers that disposed of their wastes in nearby bush is not a surprise because in open burning and conventional dump sites, wastes will often be removed by fire or environmental management authorities, but they may remain in nearby bushes for a long time (Table 6).

Two additional risk factors that can be associated with microbial contamination of TOPHFs in Ogbomoso are the level of formal education of the THMPs and the techniques of updating their knowledge and expertise. It is a popular belief that formal education should be helpful in an enterprise such as traditional herbal practice. However, the entries in Table 6 with regard to this factor have not depicted a perfect match between high level of formal education and manufacture of drugs free of contamination. This observation can be explained by possible interaction between educational attainment and other factors which ordinarily may or may not have significant association with drug contamination. As regards updating the drug manufacturers' knowledge and expertise, the statistical result is explainable in that 
significantly higher contamination (82\%) was recorded for those that embraced unscientific mode such as intuition than the observed $45 \%$ in the products of those that adopted more pragmatic approaches such as attendance at health talks, information on electronic media and the internet (Table 1). Thus, as reported by Walther et al. (2016) in Tanzania, the high contamination rate of TOPHFs in Ogbomoso, Nigeria, is also attributable to individual, environmental and systemic factors.

The findings from this study point to the fact that most of the orally consumed powdered herbal medications in Ogbomoso contain hazardous microorganisms. Meanwhile, more direct or indirect publicity is being given to herbal therapy in the nooks and crannies of Nigeria. This is also corroborated by the discovery that $96 \%$ of the 75 regular users of herbal products in the study area would like to refer other persons to the use of the drugs for their health care. While the bulk of microbial contamination observed in this study was because of Streptococcus spp., Fatema et al. (2014), after performing a time course analysis of microbiological contamination level of some oral liquid drugs in Bangladesh, reported that Streptococcal growth was the most predominant after 21 days.

It is not unusual to hear of people suffering severe reactions as a result of the use of certain herbal products. In some countries, there are little or no standards regulating either herbs or practitioners of traditional medicine, and this has created the opportunity for herbal fraud and even the sale of dangerous herbal formulations claimed as cures (Ekor 2013). The presence of pathogenic microorganisms in herbal formulations is not only undesirable as agents of propagating these dangerous organisms in humans; in certain cases, some of these microorganisms have been found to be drug-resistant (Fatema et al. 2014).

\section{Conclusion}

The use of TOPHFs is popular among the residents of Ogbomoso in Nigeria. However, the personal and environmental hygiene of the manufacturers as well as the methods by which they update their knowledge in the trade are matters for concern. This is because there was a high rate of contamination of the drugs with potentially pathogenic organisms because of insufficient quality control in the production and handling of the drugs.

\section{Acknowledgements}

The authors are grateful to the traditional herbal medicine practitioners in Ogbomoso for providing samples of the powdered drugs analysed and to Mr Muhammed Jimoh for effective coordination of the team of research assistants during questionnaire administration.

\section{Competing interests}

The authors declare that they have no financial or personal relationships that may have inappropriately influenced them in writing this article.

\section{Authors' contributions}

J.E.I. was responsible for the data collection, laboratory analyses and preparation of draft manuscript. A.T.J.O. was responsible for the conceptualisation of the research and manuscript preparation.

\section{References}

Abba, D.A., Inabo, H.I., Yakubu, S.E. \& Olonitola, O.S., 2009, 'Contamination of herbal medicinal products marketed in kaduna metropolis with selected pathogenic bacteria', African Journal of Traditional Complementary and Alternative Medicine 5, 78-82. https://doi.org/10.4314/ajtcam.v6i1.57076

Adeleye, I.A., Okogi, G. \& Ojo, E.O., 2005, 'Microbial Contamination of herbal Preparations in Lagos, Nigeria', Journal of Health, Population and Nutrition 23(3), 296-297.

Akyala, I., Ajumobi, O. \& Olayinka, A., 2014, 'Implication of Coliforms as a major public health problem in Nigeria,' Journal of Public Health and Epidemiology 6(1), 1-7, https://doi.org/10.5897/JPHE2013.0581

Bauer, R., 1998, 'Quality criteria and standardization of phytopharmaceuticals: Can acceptable drug standards be achieved?' Drug Information Journal 32(1) 101-110. https://doi.org/10.1177/009286159803200114

Baylis, C., Uyttendaele, M., Joosten, H. \& Davies, A., 2011, The Enterobacteriaceae and their significance to the food industry, Report, ILSI Europe, International Life Science Institute, viewed 01 August 2018, from http://ilsi.eu/wp-content/uploads/ sites/3/2016/06/EP-Enterobacteriaceae.pdf.

Butler, A., 2005, Focus on fecal coliform bacteria, ecology's water quality program Washington State Department of Ecology, viewed 01 August 2018, from www.ecy. wa.gov.

Ekeopara, C.A. \& Ugoha, A.M.I., 2017, 'The contributions of African traditional medicine to Nigeria's health care delivery system', Journal of Humanities and Social Science 22(5 Version 4), 32-43, viewed 01 August 2018, from http://www. iosrjournals.org/iosr-jhss/papers/Vol.\%2022\%20lssue5/Version-4/F2205043243. pdf; https://doi.org/10.4314/ajtcam.v8i5S.5

Ekor, M., 2013, 'The growing use of herbal medicines: Issues relating to adverse reactions and challenges in monitoring safety', Frontiers in Pharmacology 4(177), 177. https://doi.org/10.3389/fphar.2013.00177

Enayatifard, R., Asgarirad, H. \& Kazeni-Sani, B., 2010, 'Microbial quality of some herbal solid dosage forms', African Journal of Biotechnology 9(11), 1701-1705. https:// doi.org/10.5897/AJB10.1673

Environmental Fact Sheet, 2003, Fecal coliform as an indicator organism, New Hampshire Department of Environmental Services, viewed 04 January 2019, from www.des.nh.gov.

Fatema, K., Chakraborty, S.R., Sultana, T., Rahman, M.M., Kamali, N.M., Das, K.K. et al., 2014, 'Assessment of microbiological quality of pediatric oral liquid drugs', Journal of Pharmacognosy and Phytochemistry 3(1), 165-171.

Gautam, A. \& Bhadauria, R., 2008, 'Fungal contamination of few common stored herbal fruit samples', The Internet Journal of Nutrition and Wellness 8(1), 1-5.

Gupta, S.C., 2011, Fundamentals of statistics, 6th revised \& enlarged edn., Himalaya Publishing, Mumbai, pp. 15-21.

Idu, M., Erahbor, J.O. \& Idele, S.O., 2011, 'Microbial load of some medicinal plants sold in local markets of Benin City, Nigeria', International Journal of Medicinal and Aromatic Plants 1(3), 272-277. https://doi.org/10.4314/tjpr.v9i3.56285

Islam, M.S., Alam, M.N., Kabir, M.A.A., Nasrinm, T. \& Mia, Z., 2015, 'Qualitative and quantitative microbial load in oral liquid drugs in Bangladesh,' International Journal of Natural and Social Sciences 2(3), 54-59.

Khanom, S., Das, K.K., Banik, S. \& Noor, R., 2013, 'Microbiological analysis of liquid oral drugs available in Bangladesh', International Journal of Pharmacy and Pharmaceutical Sciences 5(4), 479-482.

Kneifel, W., Zech, E. \& Kopp, B., 2002, 'Microbial contamination of medicinal plants A review', Planta Medica 68(1), 5-15, https://doi.org/10.1055/s-2002-20060

Kunle, O., Oluyemisi, F., Egharevba, H.O. \& Ahmadu, P.O., 2012, 'Standardization of herbal medicines - A review', International Journal of Biodiversity and Conservation 4(3), 101-112, https://doi.org/10.5897/IJBC11.163

Lacoma, T., 2018, Factors that affect growth of microorganisms, viewed 12 March 2019 from https://sciencing.com/three-conitions-ideal-bacteria-growth-9122.html.

Ogunkunle, A.T.J. \& Ashiru, S.B., 2011, 'Experience and perceptions of the residents of Ogbomoso land Nigeria on the safety and efficacy of herbal medicines', Journal of Herbal Practice and Technology 1, 22-28.

Ogunsakin, J., 2015, 'A legal prognosis of child labour under the Nigerian Child's Right Act', International Affairs and Global Strategy 30, 28-37.

Okunlola, A., Adewoyin, B.A. \& Odeku, A.O., 2007, 'Evaluation of pharmaceutical and microbial qualities of some herbal medicinal products in south western Nigeria', Tropical Journal of Pharmaceutical Research 6(1), 661-670. https://doi. org/10.4314/tjpr.v6i1.14644

Onilude, A.A., Igbinadolor, R.O. \& Wakil, S.M., 2010, 'Effect of time and relative humidity on the microbial load and physical quality of cashew nuts (Anacardium occidentale L.) under storage', African Journal of Microbiology Research 4(19) 1939-1944.

Onyambu, M.O., Chepkwony, H.K., Thoithi, G.N., Ouya, G.O. \& Osanjo, G.O., 2013, 'Microbial qualities of unregulated herbal medicinal products in Kenya', College of Health Sciences. 
Onyiapat, J., Okoronkwo, I. \& Ogbonnaya, N.P., 2011, 'Complementary and alternative medicine use among adults in Enugu, Nigeria', Complementary and Alternative Medicine 11(1), 19, viewed 04 January 2019, from https://www.ncbi.nlm.nih.gov/ pmc/articles/PMC3066112; https://doi.org/10.1186/1472-6882-11-19

Oreagba, I.A., Oshikoya, K.A. \& Amachree, M., 2011, 'Herbal medicine use among urban residents in Lagos, Nigeria', Complementary and Alternative Medicine 11(1), 117, viewed 04 January 2019, from https://www.ncbi.nlm.nih.gov/pmc/ articles/PMC3252251; https://doi.org/10.1186/1472-6882-11-117

Shweta, S., Gupta, A., Kataria, R. \& Jain, Y., 2017, 'Isolation, identification and characterization of antibiotic producing bacteria from soil at $\mathrm{Dr} C \vee$ Raman University Campus Bilaspur (C.G.)', World Journal of Pharmaceutical Research 6(8), 1004-1011. https://doi.org/10.20959/wjpr20178-8806

Strocel, A., 2013, Nurturing natural inquisitiveness, Vancouver Mom, viewed 03 January 2019, from https://www.vancouvermom.ca/for-kids/nurturing-naturalinquisitiveness/.
SCALE, 2018, Behaviour management important facts, Student Coalition for Action in Literacy Education (SCALE), viewed from https://readwrite.org.

Wachtel-Galor, S. \& Benzie, I.F.F., 2011, 'Herbal medicine: An introduction to its history, usage, regulation, current trends, and research needs', in Herbal medicine: Biomolecular and clinical aspects, 2nd edn., Taylor and Francis Group, NCB (National Centre for Biotechnology Information) Books, viewed 04 January 2019, from https://www.ncbi.nlm.nih.gov/books/NBK92773/.

Walther, C., Marwa, K.J., Seni, J., Hamis, P., Silago, V., Mshana, S.E. et al., 2016, 'Microbial contamination of traditional liquid herbal medicinal products marketed in Mwanza city: Magnitude and risk factors', Pan African Medical Journal 23, 65-71. https://doi. org/10.11604/pamj.2016.23.65.7917

WHO, 2004, Guidelines on Good Agricultural and Collection Practices (GACP) for medicinal plants, World Health Organization, Geneva.

World Health Organization, 1998, Quality control methods for medicinal plant materials, World Health Organization, Geneva. 